\title{
Pilot Study: Bloom's Digital Taxonomy Application for an Online Art Project
}

\author{
Somi Lee \\ Faculty of Fine Arts, Concordia University
}

\begin{abstract}
This pilot study is about finding affordances and challenges when assisting amateur artists building their art portfolio with and through social media sites and other resources available in the Internet. As there is high demand in computer and communication technology in the field of art education [1], [2], my research seeks to respond to expand the learning possibilities within online environment.
\end{abstract}

\section{Introduction}

This pilot study is about finding affordances and challenges when assisting amateur artists building their art portfolio with and through social media sites and other resources available in the Internet. As there is high demand in computer and communication technology in the field of art education [1], [2], my research seeks to respond to expand the learning possibilities within online environment.

The purpose of this Design-Based Research project is twofold. One was finding affordances and limitations in guiding the artists. The other was to craft a robust and instructional standard guideline and a teaching method that could be easily employed and adapted in a wide range of online learning environments. Both purposes aim to build up on an avenue of learning environment where students and artists could express and display their work with confidence.

There were one male artist and three female artists. The participants were recruited from my personal network. Three of them were Montreal based whereas one was Toronto based. The questions that arose during the project procedure are "What functions do a particular website serve and how can social media sites be utilized more effectively to boost participants' engagement", and "How do facilitators make the participants more comfortable posting their work". Some were answered from this research while some were left unanswered.

\section{Research Activity}

Over the six week period, the participants were encouraged to create artwork, post the pieces on the 'invitation-only' project website called Art Exhibition Project 2015 on basecamp, where their user IDs were the only indication of their identities. They exchanged feedback with other group members, completed a two set of surveys, partook in two to three individual video conferences, and engaged in other tasks. These tasks were suited to carry out the project systematically and the integral practice was designed to motivate participants to create artwork and inspire them in a more constructive way. As such, having an art show was assigned to participants as a mutual goal.

$\mathrm{I}$, as a co-participant, took the role of facilitator and maintained an equal footing with the participants; Aerial, Creamo, Mat eng, and Sese A. As a co-participant, I also posted visual images and comments, engaged in art analyzing activities, and uploaded useful art resources such as art exhibition information, and contemporary artists paintings for other members to inspire participants. As Dargham et al. state, "personalize instruction to be relevant to the needs of individual participants, which is also part of the instructor's duties" [7], my responsibilities for the activities reflected their pedagogy of meeting participants' individual needs. As a facilitator, I opened a project website where participants could post their visual images and exchange feedback (see Figure 1). I created activities and assigned participants various tasks, surveys, I sent them email notifications about important dates, uploaded instructional clips for that were relevant to each individual's need, and responded to participants' questions and commentaries. In an attempt to communicate with participants, Skype were used for all two sets of interviews with all four participants and the interviews were recorded with my cellular phone. Facebook, Smartphone Text messages and phone calls, and Gmail account were used predominantly to communicate with participants. In terms of addressing participants' uncertainty of their progress and artwork, I provided success criteria for the participant to understand their adequacy in art-making processes and their outcomes. For participants, their success criteria were to display and present their work to the public with confidence. When measuring the degree of participation, the frequency of task engagement was opted for the lever. According to Shavelson and Towne [19], DBR poses significant questions that could be investigated 
empirically. My research encompassed the empirical process that participants were deeply involved in theory making process.

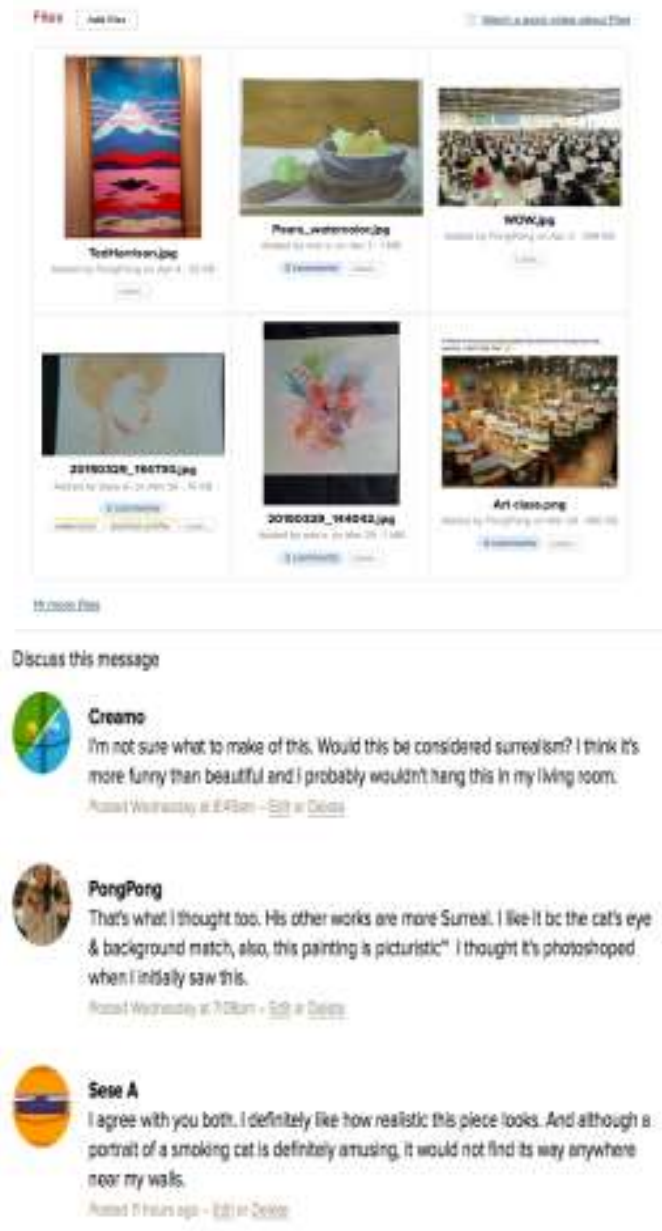

Figure 1. Project Website Interface

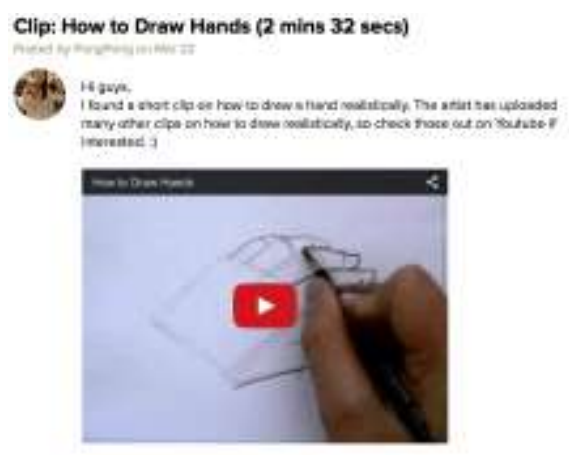

Figure 2. Instructional Clip on Youtube
For each iteration of the project, I took participants' suggestions into consideration congruent with my personal judgment and with gleaned ideas from literature when molding the project.

\section{Bloom's Digital Taxonomy}

For this study, I adopted the Bloom's Digital Taxonomy (BDT) 2008 when constructing each assignment. This pilot study was used to examine the effectiveness of BDT in enhancing artists' artistic merits and developing their capacity to assess their own work.

Bloom's Taxonomy (BT) was developed in 1956 by Benjamin Bloom, an educational psychologist from the University of Chicago [12], [4]. The taxonomy is intended not only to measure students' abilities and knowledge [9] but also to help teachers to develop a curriculum that facilitates students' learning [12],[20]. The classifications suggest an instructional delivery method and are used for building a strong assessment tool [4], [9].

BT has been revised by Lorin Anderson and David Krothwohl in 2000, and later by Andrew Churches in 2008. Anderson, a former student of Bloom's, updated BT with his colleagues to add relevance to 21 st century students, teachers, and a much broader audience [9]. It was re-named Bloom's Revised Taxonomy. Similarly, Andrew Churches digitized the taxonomy to respond to today's learning needs [18] by incorporating Information and Communications Technologies, or ICT [18],[9] into the classification. This version was named Bloom's Digital Taxonomy (BDT). BT is based on the principle that knowledge development is accomplished through one or more of the three psychological domains: (1) the cognitive domain, where learners process information, knowledge and mental skills, (2) the affective domain, which refers to learners' attitudes and feelings, and (3) the psychomotor domain, which refers to physical skills [12], [4],[9] Moreover, there are six major categories of cognitive processes: knowledge, comprehension, application, analysis, synthesis, and evaluation. This list begins with the simplest category and ends with the most complex. In terms of BDT application, implementing technology to help students become more competent in the digital world is not a new concept. The Ontario Arts Council has been advocating the implementation of technology in art education before the advent of BDT.

Students in Ontario have been encouraged to learn how to use computers and video equipment to plan and create art. Moreover, the Toronto District School board introduced Information and Communications Technologies standards in 2008 that accommodate BDT. These standards include strategies for integrating technology into the 
existing curriculum [18]. Consequently, the focus of BDT application is to prepare our students to become knowledgeable in using digital tools [18].

For my proposed study, I will use some of the digital tools that Churches introduced in his BDT: wikis, classroom blogs, collaborative document tools, social networks, and learning management [4]. Also, advantages of using these web-based tools in the process of portfolio development are that they can often be free and promote collaboration among students [4], [15]. I will adopt Bloom's Digital Taxonomy (BDT) 2008 when constructing each lesson. BDT is a revised version of the Bloom's Taxonomy (BT) that is composed of six domains of thinking skills and objectives for learning in addition to expanded elements, such as blogging, commenting, posting, and subscribing. BT was modified by Andrew Churches in order to satisfy the learning expectations of the digital age. The six domains of taxonomy include learning, teaching, and assessing: creating, evaluating, analyzing, applying, understanding, and remembering [4]. Each domain consists of sub- elements of learning: (1) remembering includes recognizing, listing, describing, networking, favoriting, searching, (2) understanding includes interpreting, summarizing, blogging, tweeting, tagging, commenting, etc. (3) applying includes implementing, using, loading, uploading, sharing, etc. (4) analyzing includes comparing, linking, validating, media clipping, (5) evaluating includes checking, critiquing, experimenting, blog commenting, reviewing, posting, etc. (6) creating includes designing, constructing, making, animating, etc. [4], [18]. In their art creation processes, students should apply (1), (2), and (6): remembering sources of inspiration found through searches, understanding issues by comprehensive interpretation and keeping digital journals/blogs, and creating and designing art pieces that will be selected to use. Furthermore, sharpening students' critical eye for selecting pieces art portfolio pieces will be one of the core parts of the project. Students should learn how to reflect on their work as art creation and skill development progress. In the context of students' assessment of their own artwork when selecting pieces for their portfolio, students should apply (2), (4) and (5): understanding their own work while explaining it to each other, analyzing their artwork by linking it to historical or contemporary works of art that reflect similar societal values, and evaluating their work by posting it online and networking with others.

I propose that BDT is an effective springboard for teachers when constructing lessons, especially for students in Ontario. Ontario Curriculum documents are congruent with BT. For instance, the Toronto District School Board recently implemented ICT (Information and
Communications Technologies) guidelines, which accommodate BDT guidelines. That is, BDT application for this proposed research will contribute to the online community to improve students' artistic merits and develop their capacity to assess their own work.

\section{Data Analysis}

As for the data, three levels of data were implemented. The data level I includes interview transcriptions, dialogues exchanges between participant-participant and participant-co-participant (me). The data level II includes review of literature topics on video conferencing, elearning environment, cyberspace, and portfolio assessment. The forms of publication include thesis dissertations, art education journals such as NSEAD, Education policy review, and books. The data level III includes daily digital journal documenting on email communications, participants' surveys evaluating the project, their encountered issues, my reflection on participants' commitment to each activity and their level of enthusiasm toward each task, and any noticeable changes. This was done simultaneously and identified participants' pattern of engagement and estimated the factors and other variables. Keeping a journal helped in organizing my interpretation, process, idea and navigate for next steps and modify process.

From the data level I, transcribing the first interviews was an enlightening experience that steered direction of the second interviews and made them more solid and participant-centered. For instance, I found an apparent glitch from the first interview; the way I posed questions was inappropriate as there were many leading questions with predetermined ideas.

I later reformulated questions and took my position as an active listener in order to minimize my personal bias [11]. For the data level II, pre-existing theory and findings were integrated in the process of data analysis by retrospective analysis and revisiting relevant literature and theories. For the data level III, from my journal about the first survey, I developed simple codes such as Worries/Concerns, Skills, Time, Schedule, Technology, which later came under sophisticated categories such as, Affordances, Limitations, Variables, Confidence level, Expectations, Method of Communication, Issues, Solutions. These codes were then compared against each other through ongoing field observations.

The data analysis revolved around my journal (Data level III) in conjunction with a literature review (Data level II). Simultaneous data collection includes participants' perspectives about the activities and their engagement. I 
asked them to read the draft of my journal and check my interpretation of their data. My reason for integrating their opinions is to allow the voice of the participants to inform the direction of research. A constant comparison process was utilized. The comparison process enabled me to group and differentiate various data. For Data level I, the interview transcript was analyzed 'word for word' and digitally kept in colour-coded folders.

Patterns, and Method of Solving Problems; which generated cohesiveness in answering my research questions. The concepts, categories and themes for this project were identified and developed while the research was being conducted and then diverged into categories.

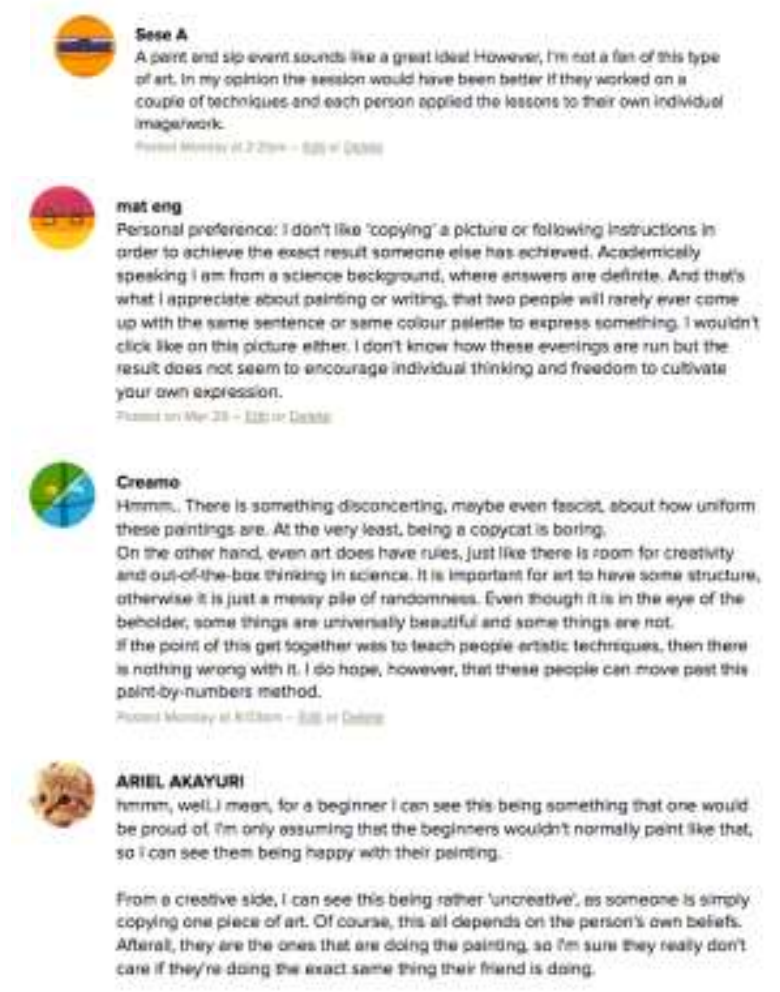

Figure 3. Participants' Commentaries

Moreover, my questions, guidelines, and activities were formulated and reformulated based on an ongoing dialogues and participants' inclinations (see Figure 3). The following image is a screen capture of participants' comments on a wine and sip studio practice. These comments reflect participants' educational backgrounds, occupations, schedules, preferences, and personalities.

\section{Findings in Strategic Planning and Instruction}

Palloff \& Pratt state that "if clear guidelines are not presented, students can become confused and disorganized and the learning process will suffer" [4]. Indeed, I found that a project guideline for this study with clear objectives, expectations for the project, and brief explanations of each activity assisted participants in coordinating their portfolio creation in correspondence to the guideline. It further helped them arrange their plan their work to fit in their busy schedules [7]. In terms of schedule, advanced notification of deadlines was practical and minimized equivocations and kept them engaged on task [5].

Having a face-to-face meeting with the participants in the beginning helped put the participants at ease by reducing the obtrusiveness of the project. It also provided them an opportunity to understand the project and learn about me and my role as a co-participant, and what kind of assistance they could get from the project. The face-to-face meeting provided me an opportunity get to know the participants' personal preferences and backgrounds. This was beneficial when tailoring individualized instructions and questions [5].

Collison et al. underscore the duty and role of a facilitator in forming a thriving online community [6]. Through my role as a co-participant and facilitator, I strived to create a friendly and welcoming environment by using a casual tone and using common "Net Jargon" in the commentary such as ":)" and "lol". Also, I attempted to balance the distribution of my input with participants' interactions with each other. As such, I limited the amount of my posting and waited for participants to comment in order for them to use initiative and interact. Furthermore, active participation was desired and encouraged throughout the project. In this context, peer interaction was imperative in making the online community active and facilitated the conversations. The peer interaction on the project website was contingent with participants' postings, responses, questions, and activities [7]. These activities gradually advanced their dialogue quality and resulted in a dynamic environment that was reciprocal. In the beginning, I had to initiate conversation, but it slowly shifted to participant-centered as participants' dialogue exchange became more frequent. From this ramification, I learned to be patient and learned participants need time to get accustomed to the new environment before participating. 


\subsection{Findings in Relationship between Level of Confidence in their Artistic Ability and Participation Frequency}

The strength in artistic merit is not heavily linked to participants' willingness to participate and their active engagement. However, the participants' level of confidence in their artistic ability plays a significant role in their engagement and completion of tasks. When a participant is confident with their outcome, he/she is prone to post visual images, respond to other members in the group, ask questions and make suggestions more actively. As such, Creamo, who expressed his technology incompetency during the first meeting, was inclined to troubleshoot a technology issue he encountered in order to finish the task. On the other hand, when a participant felt uncertain about their artistic strength, they displayed a degree of reluctance in posting visual work and interacted less. Furthermore, participants who displayed a low level of confidence completed a series of written tasks regularly. This indicates their acknowledgement of their responsibilities to finish work on time and their passion toward the project, and undermines the possibilities of their disinterest in the activities. One example for this is Mat eng and Sese A, who both constantly expressed concerns about their artistic ability, always completed short answer questions, surveys, and weekly art critique activities before the deadlines. While Sese A completed her written work she did not post a single image until three weeks after the official start date. This could suggest that while she was initially confident with her written work, it took her three weeks to develop confidence in her visual work.

\subsection{Findings in Affordances}

In terms of affordances, this research further confirms Castro's [3] findings of students' learning from looking at each others' work and their commentary about the posted image. The feedback participants received, including comments posted on each other's images, helped them to start a conversation and led them to inquire in depth about the image in question [10]. Their feedback became richer and more descriptive as the project progressed. In her interview, Sese A expressed that learning from each others' remarks on works was the major advantage of this project. The outcome of the project confirms Castro's theory that the act of looking and the act of dialogic interaction online allows students to learn by looking at each others' work and commentaries [3].
Secondly, when it came to looking at and responding to artwork, participants felt unfettered when contemplating the artwork before providing feedback. The online environment allowed participants more time [16] to view, ponder, and write. Furthermore, compared to traditional classroom settings, all participants got an equal chance [16], [17] and time to discuss the posted image in question. For example, Ariel, during the video conference, described that one of the major benefits of this online environment for her was that she could revisit a peer's artwork as many times as she needed before making a comment.

Thirdly, this type of goal-oriented project allowed the participants to build a routine of regularly practicing art [10]. Giving deadlines was a good strategy to engage them to complete assigned tasks. During Mat eng's interview, she indicated that "building a habit of doing art more regularly" was the main thing she acquired from the project. Also, Cremo remarked that having a public exhibition as a goal, acted as a catalyst for making sure his work was good as he did not want to display "shabby paintings" to the public. From these remarks, I concur this type of goal-oriented project makes participants more serious, keeps them on track, and holds them accountable for completing their work. This validates that online community could provide the participants an avenue to complete their goals cooperatively [13]. Also, the online environment rendered our busy schedule surmountable so we were able to carry out our project successfully.

\subsection{Findings in Limitations}

The most apparent limitation that was uncovered through the project was the lack of communication, for example, participants did not come forward with their concerns unless otherwise asked. It was easy for participants to hide their concerns and difficult for me to notice issues the participants were encountering in an online community. This was detrimental in some degree and sometimes led to a misunderstanding between participants and myself. As such, I assumed participants were not engaging in an activity due to their disinterest, however, it turned out they were less confident. Sese A during her last interview, she displayed discomfort about posting images, "because I am a perfectionist, I want to make sure it looks okay before I post [artwork]."

Their concerns came forward and were sorted out mostly during the individual video conferences, their level of disclosure affected their peer interaction process. Not sharing their concerns regarding the activities impinged upon group interactivity and delayed an agree-upon project agenda. As such, Sese A postponed her image posting because she was doubtful about the integrity and readiness 
of her work. However, this caused her to miss out on valuable feedback from others during the first three week period. This could have been avoided had she consulted with me earlier. I would have encouraged her to post her work as it would be beneficial for her regardless of the stage of her project.

This point leads to the second limitation. I find a faceto-face meeting often transcends the limits of online conversation and evokes what cannot be articulated in the online community at certain points. It is legitimate that online environments enable them to proceed with their task [7] but at the same time, it develops resistance to face-toface meetings as their sub-consciousness is fixated in the online situation. As such, participants did not find it necessary to get together in person which caused them to miss opportunities to look at others' work in real life before the show. Their reluctance to meet face to face made it difficult for me to arrange such meetings, and it limited their ability to build familiarity among participants and enrich the potential of the project activity.

\section{The implications of the pilot study results for my ongoing research plans}

From these findings, I made a standard for mentoring students building their art portfolio that I would implement for future research. This could be utilized after some modifications toward other types of portfolios, such as: a professional art portfolio for gallery submissions and contests, pre-service teacher art portfolios, and job interview art portfolios. However, I will focus on my future research, which will be held in Emily Carr Secondary School within York Region School Board in Ontario. Due to the fact that the research will be conducted with school-aged students, seventeen to eighteen, the standard embraces and aims at that age group. I will be more strict about my rules and more rules will be employed. Such an example is that the lessons and deadlines will be less negotiable compare to that of adult projects.

\section{Relevance of this project for the thesis plans}

My proposed thesis is to find the affordances and limitations in mentoring students with and through Social Media Sites and digital technology in developing their art portfolios for Art University entry. For this reason, this pilot study is aligned with the thesis plan impeccably in the context of methodology; Design-Based Research (DBR) and goal-oriented project within the online community.
The pilot study was a smaller scale for my future research with different age group. Another discrepancy is the location; one group is in Montreal while the other group is in Ontario. This pilot study is a worthwhile experience. The biggest gains from this study are that I have realized my capacity of being an online community facilitator and honed my skills in technology proficiency. Equally important, I find myself familiar with the research process and the online environment from this small scale study with my friends.

\section{Recommendations for further research}

For further research, I will focus on the aspect of online presentation of students' art portfolios. This will include how to make students feel more comfortable when displaying their works to anonymous people in the virtual environment. Furthermore, in response to some of the art universities' Art portfolio online submission methods, I will look into discovering the technical strategies in presenting their work effectively such as the pixel [2], size of the work, and the method of submission in a USB key or $\mathrm{CD}$.

\section{References}

[1] Anarki, F., "Developing an Effective and Efficient eLearning Platform", International Journal of The Computer, the Internet and Management, 12 (2), 2004. pp. 57-63.

[2] Behera, A., "E-and M-Learning: A comparative study", International Journal on New Trends in Education and Their Implications, 4(3), 2013.

[3] Castro, J. C., "An inquiry into knowing, learning, and teaching art through new and social media", 2009.

[4] Churches, A., (2008), "Bloom's Digital Taxonomy". http://edorigami. wikispaces.com/file/view/bloom\%27s+Digital+t axonomy+v3.01.pdf

[5] Cole, C., Ray, K., \& Zanetis, J., "Videoconferencing for K-12 Classrooms: A Program Development Guide", International Society for Technology in Education. Eugene, Oregon, 2004.

[6] Collison, G., Elbaum, B., Haavind, S., \& Tinker, R, "Facilitating Online Learning: Effective Strategies for Moderators", Atwood Publishing. US, 2000.

[7] Dargham, J., Saeed, D., \& Mcheik, H., "E-Learning at school level: Challenges and Benefits", The 13th International Arab Conference on Information Technology. SCIT.2012.ISSN: 18120857, 2012. 
[8] Ezzy, D., "Qualitative Analysis. Practice and Innovation". Routledge. 2002, pp. 10, 61-79, $88-110$.

[9] Forehand, M., "Bloom's taxonomy”, Emerging perspectives on learning, teaching, and technology, 2010, pp. 41-47.

[10] Gitomer, D., Grosh, D., and Price, K., "Portfolio Culture in Arts Education", Art Education, 45(1), 1992. pp.7-15.

[11] Glaser, B.G., "Theoretical sensitivity: Advances in the methodology of grounded theory", Sociology Pr, 1978.

[12] Krathwohl, D. R., "A revision of Bloom's taxonomy: An overview". Theory into practice, 41(4), 2002, pp. 212-218.

[13] Marschalek, D., "Four Learning Environments for the Contemporary Art Education Classroom: Studio, Information, Planning, and Electronic", Art Education, Vol. 57 (3), 2004, pp. $33-41$.

[14] Palloff, R., Pratt, K., "Lessons from the Cyberspace Classroom: The Realities of online Teaching", Jossey-Bass. A wiley Companay. San Francisco, 2001.

[15] Skiba, D. J., "Bloom's digital taxonomy and word clouds", Nursing education perspectives, 34(4), 2013, pp.277-280.

[16] TeacherStream LLC., (2009). Mastering online board facilitation. Eutopia-OnlineLearning. www.edutopia.org/pdfs/ stw/edutopia-onlinelearning-mastering-online-discussion-boardfacilitation.pdf

[17] The Design-Based Research Collective, "Design-Based Research: An Emerging Paradigm for Educational Inquiry”.

[18] Toronto District School Board, "TDSB ICT Standards: Digital Learning for Kindergarten to Grade 12", Toronto District School Board IT Services: Teaching and Learning with Technology, 2007. Educational Researcher, Vol. 32, No. 1, 2003, pp. 5-8.

[19] Towne, L., \& Shavelson, R. J., (Eds.), "Scientific research in education", National Academies Press, 2002.

[20] Vieyra, G., "A Dialectical Interpretation of Factual Knowledge in Vygotskyan”, 2006. 